\title{
Factors determining the surface oil concentration of encapsulated lipid particles: impact of the emulsion oil droplet size
}

\author{
Annika Linke $^{1} \cdot$ Jochen Weiss $^{2} \cdot$ Reinhard Kohlus $^{1}$
}

Received: 10 February 2020 / Revised: 16 June 2020 / Accepted: 20 June 2020 / Published online: 13 July 2020

(c) The Author(s) 2020

\begin{abstract}
Microencapsulation of oxidation sensitive oils aims to separate lipids from the environmental oxygen by embedding oil droplets in a solid matrix, which builds a physical barrier. Some oil droplets are not fully incorporated and are in contact with the powder surface generating surface oil. It is proposed that the probability of oil droplets being in contact with the particle surface increases with the oil droplet size. The aim of the study is to investigate the impact of the oil droplet size on the encapsulation efficiency (EE). Two sets of feed emulsions differing in the applied homogenization pressure and in the protein to oil ratio were spray dried using a pilot plant spray dryer. The oil droplet size of the emulsion was determined by static light scattering (SLS). In addition, nuclear magnetic resonance (NMR) was used to measure the $d_{3,2}$ of oil droplets in the emulsion and in the powder before and after surface oil removal. Encapsulates were analyzed regarding $\mathrm{a}_{\mathrm{w}}$, moisture content, particle size, oil load and EE. The oil droplet size in the emulsion decreased with increasing protein to oil ratio as well as with the homogenization pressure. Large oil droplets and in particular droplet clusters resulted in more non-encapsulated oil. The experimentally determined EE was in accordance with the theoretical one, calculated based on the droplet and particle diameter. For emulsions with a diameter $>1 \mu \mathrm{m}$, the $d_{3,2}$ decreased in the powder and further by removing the surface oil, which was related to the deformation of oil droplets contributing to the non-encapsulated oil.
\end{abstract}

Keywords Microencapsulation $\cdot$ Oil droplet size $\cdot$ Encapsulation efficiency $\cdot$ NMR $\cdot$ Spray drying

\section{Introduction}

Polyunsaturated fatty acids are prone to oxidation. An established technique to protect these lipids is microencapsulation by spray drying an $\mathrm{O} / \mathrm{W}$ emulsion, which contains dissolved solids in the continuous phase. After atomization, the emulsion feed droplets get in contact with the hot drying medium. The water in the continuous phase evaporates and the dissolved solids build a wall surrounding the oil [1-3]. After drying the oil droplets are embedded within a matrix, which acts as a physical barrier between the environmental oxygen and the oil. In order to react with each other and promote

Annika Linke

annika.linke@uni-hohenheim.de

1 Process Engineering and Food Powders, Institute of Food Science and Biotechnology, University of Hohenheim, Stuttgart, Germany

2 Food Physics and Meat Science, Institute of Food Science and Biotechnology, University of Hohenheim, Stuttgart, Germany oxidation, the oxygen first has to solubilize in the matrix followed by diffusion towards and into the oil droplets $[3,4]$.

Some oil droplets are not fully incorporated within the matrix and are in contact with the powder particle surface. The so-called surface-, free-, extractable or non-encapsulated oil is exposed to the environmental oxygen and oxidizes rapidly [3, 5-10]. Therefore, it is crucial to understand how non-encapsulated oil is generated and how it can be minimized or eliminated. A common parameter to access the success of microencapsulation is the encapsulation efficiency (EE), which is defined as the ratio of the encapsulated- to the total oil $[2,11]$. It is an indirect measure for the amount of non-encapsulated oil taken into account the total oil load.

Apart from atomization and drying conditions, one of the key parameters determining the EE and therefore the amount of non-encapsulated oil is the size and stability of oil droplets. In literature it has been stated, that stable and small oil droplets result in a more efficient encapsulation [2, $3,11-17]$. This phenomenon is often explained by disruption of large oil droplets during atomization $[15,18,19]$. This 
explanation is used for both, encapsulating non-volatile oils and flavors, even though they might behave differently during the encapsulation process $[2,3]$.

An alternative concept has been proposed, assuming that the amount of surface oil is dependent on the probability of the oil droplets being in contact with the powder particle surface $[18,20]$. Linke et al. have demonstrated, that a large powder particles result in less non-encapsulated oil, which is in accordance with a theoretical encapsulation efficiency calculated based on the probability. With respect to the oil droplet size, it has been proposed that the likelihood of small oil droplets being in contact with the particle surface is lower resulting in a higher EE [20].

This study investigates, if the proposed concept is valid for different oil droplet diameters. For that purpose, two independent sets of feed emulsions are prepared to change the emulsion droplet size in different ways and thereby minimize secondary effects. One set is varied in the protein to oil ratio, the other in the homogenization pressure. Apart from static light scattering (SLS), the Sauter mean diameter of oil droplets is determined by Pulsed Field Gradient-Nuclear Magnetic Resonance (NMR), which allows measuring the average size of oil droplets in the emulsion and in the powder. Thus, in contrast to other studies, the effect of spray drying on the droplet size is evaluated without reconstituting the powder.

\section{Materials and methods}

\section{Materials}

High quality fish oil (Omega Oil 1812 TG Gold) was provided by BASF Personal Care and Nutrition GmbH (Illertissen, Germany). Maltodextrin DE 21 (AGENABON) and soy protein isolate (Vegacon 90) were obtained from Agrana $\mathrm{GmbH}$ (Frankfurt/Main, Germany) and Eurosoy GmbH (Hamburg, Germany), respectively. For chemical analysis n-Hexane (ROTISOLV® HPLC) was obtained from Carl Roth GmbH + Co. KG (Karlsruhe, Germany).

\section{Encapsulation process}

Emulsion and powder preparation were conducted as described by Linke et al. [6]. In brief, the amount of soy protein isolate in the feed emulsion was varied $[0.35,0.75$, $1.25,2.25$ and $4 \%(\mathrm{w} / \mathrm{w})]$, which corresponds to a protein to oil ratio between 0.02 and $0.22(\mathrm{w} / \mathrm{w})$. The protein was dissolved in distilled water and maltodextrin DE 21 added to reach a solid concentration of $27 \%(\mathrm{w} / \mathrm{w})$. After dispersing the fish oil [18\% (w/w)], the coarse emulsion was homogenized in three passes using a high pressure homogenizer (HL 1.3-400KX, HST Maschinenbau GmbH, Dassow,
Germany) operated at different pressures $(0.5,2.0,7.5,12.5$ and $25 \mathrm{MPa}$ ). The ratio between the first and second pressure stage was $5 / 1$. The default settings for the protein to oil ratio and homogenization pressure were $0.13(\mathrm{w} / \mathrm{w})$ and 12.5 MPa, respectively.

Emulsions were spray dried by using a pilot plant dryer (type FSD 4.0, GEA-Niro Copenhagen, Denmark) operated at an airflow rate of $200 \mathrm{~kg} \mathrm{~h}^{-1}$ in the closed loop set up. The feed emulsions were atomized using a two-fluid nozzle with a nozzle diameter of $2 \mathrm{~mm}$ (ex GEA-Niro). Inlet and outlet temperature were set to 160 and $85^{\circ} \mathrm{C}$, respectively. The feed flow rate was $11.42 \pm 0.44 \mathrm{~kg} \mathrm{~h}^{-1}$.

\section{Emulsion characterization}

\section{Viscosity}

The emulsion viscosity was measured by conducting a shear rate ramp using a Kinexus ultra + (Malvern Instruments, Herrenberg, Germany) equipped with a double gap geometry according to the method described by Linke et al. [20].

\section{Oil droplet size}

Static light scattering (SLS) A Mastersizer 2000 (Malvern Instruments Ltd, UK) was used to determine the size distribution of oil droplets by SLS. Data were analysed according to Mie-theory considering a refractive index of 1.481. Of each emulsion three samples were measured in triplicate and the $d_{3,2}$ and $d_{3,0}$ of oil droplets acquired.

Pulsed field gradient-Nuclear magnetic resonance (NMR) A Bruker minispec MQ20 NMR Analyzer (Bruker, Rheinstetten, Germany) equipped with a controlled pulsed gradient unit and a probe head H20-10-25-AVXG was operated at $20{ }^{\circ} \mathrm{C}$. The oil droplet size of emulsions and within powders was determined according to the procedure described by Linke et al. [21]. In brief, the application 'oil droplets' provided by Bruker was calibrated by using a doped water sample $\left(0.5 \% \mathrm{CuSO}_{4} \cdot 5 \mathrm{H}_{2} \mathrm{O}\right)$. The self-diffusion coefficient of the fish oil was $10.2 \cdot 10^{-12} \mathrm{~m}^{2} \mathrm{~s}^{-1}$. Feed emulsions and powder particles were tempered at $20{ }^{\circ} \mathrm{C}$ and the $d_{3,2}$ calculated based on the acquired $d_{3,3}$ and $\sigma$.

\section{Light microscopy}

Light microscope images of three exemplary emulsions [protein to oil ratio of $0.02,0.04$ and $0.13(\mathrm{w} / \mathrm{w})]$ with a 40 -fold magnification were taken using a microscope Primovert (Carl Zeiss AG, Oberkochen, Germany). 


\section{Powder characterization}

\section{Moisture content and water activity}

The product moisture was determined by Karl-FischerTitration (Titrando 841 and 803 Ti Stand, Metrohm GmbH \& Co. KG, Filderstadt, Germany). The powder was dissolved in hydranal formamide and hydranal solvent (2:1 v/v) provided by Honeywell (Offenbach, Germany). Formamide was added to avoid a reaction delay caused by the presence of maltodextrin. The water activity was measured using a AW SPRINT TH-500 (Novasina AG, Lachen, Schweiz) operated at $25^{\circ} \mathrm{C}$.

\section{Powder particle size}

A Mastersizer 2000 (Malvern Instruments Ltd, UK) was used to determine the powder particle size by dispersing the powder in $96 \%(\mathrm{v} / \mathrm{v})$ ethanol. Of each powder three samples were measured in triplicate. Data were analyzed according to Fraunhofer theory and expressed as $\mathrm{d}_{50,3}$.

\section{Particle morphology}

Scanning electron microscopy images of three exemplary powders [protein to oil ratio of $0.02,0.04$ and $0.13(w / w)$ ] were obtained using a JSM-IT100 (JEOL GmbH, Freising, Germany) operated in the SED mode under high vacuum. Images of the particle morphology with and without nonencapsulated oil were taken with an 850-fold magnification by applying an acceleration voltage of $3.0 \mathrm{kV}$. Images with a 1500 -fold magnification of the particle inside were taken at $5.0 \mathrm{kV}$ after cutting.

\section{Oil load}

The oil load of powders was measured by a method described by Linke et al. [21]. Briefly, a Bruker Minispec MQ20 NMR Analyzer (Bruker, Rheinstetten, Germany) equipped with an absolute probe head H20-18-25-A1 was operated at $40{ }^{\circ} \mathrm{C}$. Data were acquired by the software application data oil program provided by Bruker. The $90^{\circ}$ and $180^{\circ}$ pulse length were set to of 19.62 and $39.92 \mu \mathrm{s}$, respectively, separated by $3.5 \mathrm{~ms} .16$ scans with a recycle delay of $2 \mathrm{~s}$ were applied. Of each powder two samples were weighed into tubes and tempered at $40{ }^{\circ} \mathrm{C}$ for $45 \mathrm{~min}$. The NMR intensity was measured in triplicate and the oil load determined based on a calibration with different masses of bulk fish oil.

\section{Non-encapsulated oil and encapsulation efficiency}

The non-encapsulated oil was removed by shaking approximately $1 \mathrm{~g}$ powder in $10 \mathrm{~mL} n$-Hexane for $2 \mathrm{~min}$. After filtration the retained powder was washed three times with $10 \mathrm{~mL} n$-Hexane. The remaining oil was measured as previously described for the oil load. The amount of surface oil was calculated by subtracting the remaining amount of oil in the washed powder from the total oil load. Dividing the amount of encapsulated oil by the total oil load times 100 resulted in the EE.

\section{Statistical analysis}

Unless otherwise reported, all measurements were performed in triplicate and the results presented as mean \pm standard deviation. OriginPro 2017 (OriginLab Corporation, Northampton, MA, USA) was used to test data on normality according to Shapiro-Wilk test. As for all data normality could not be rejected, statistically significant correlations were determined by Pearson's correlation coefficient $(r)$ for a confidence interval of $95 \%$. In addition, the corresponding $p$-value was reported. Statistically significant differences were identified using a Mood's Median test.

\section{Results and discussion}

\section{Impact of modified parameters on emulsion properties}

\section{Oil droplet size}

In order to change the oil droplet size in the feed emulsions, the amount of soy protein isolate and the homogenization pressure were varied. Figure 1 shows the oil droplet size distribution measured by SLS for the modified protein to oil ratio (a) and the homogenization pressure (b).

The ultimate range of oil droplet diameters was approximately between 0.2 and $100 \mu \mathrm{m}$. Increasing the soy protein isolate concentration and the homogenization pressure resulted in an obvious shift towards smaller oil droplets. The lowest protein to oil ratio of 0.02 led to droplets diameters between 10 and $100 \mu \mathrm{m}$, whereas a range from 0.2 to $4 \mu \mathrm{m}$ was obtained for a ratio of 0.22 . For emulsions homogenized at different pressure levels, oil droplet diameters between approximately 0.2 and $15 \mu \mathrm{m}$ were obtained. Thus, the effect on the oil droplet size was less pronounced compared to the modified protein concentration.

Ideally one would like to keep the shape of the size distribution similar and only vary the mean diameter. In case of the modified homogenization pressure, all PSD's were similar except for the emulsion homogenized at the highest 

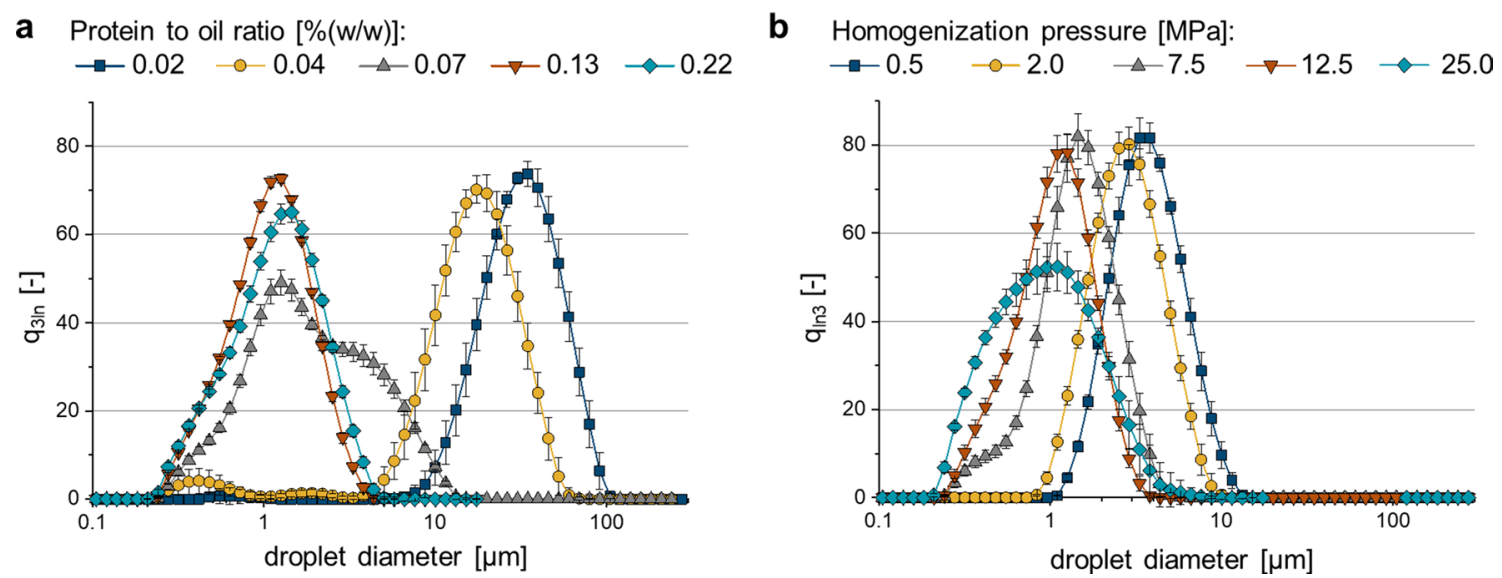

Fig. 1 Size distribution of oil droplets in feed emulsions differing in the protein to oil ratio (a) and in the applied homogenization pressure (b) measured by SLS

pressure, which resulted in a less narrow distribution. When varying the protein to oil ratio to trigger the change of oil droplet size, using $0.07(\mathrm{w} / \mathrm{w})$ led to a different shape than the other PSD's.

The change in the droplet size was summarized by the Sauter mean diameter (Fig. 2). The $d_{3,2}$ (determined by SLS) decreased with an increasing protein to oil ratio and homogenization pressure until a droplet diameter $\leq 1 \mu \mathrm{m}$ was reached. This was expected and is in accordance with data reported in literature [12, 16, 17, 22-29]. As soy protein acts as an emulsifier, it adsorbs at the interfacial area and thereby stabilizes the generated oil droplets. An insufficient amount of emulsifier leads to recoalescence and therefore large oil droplets, due to incomplete oil surface coverage. For fixed homogenization conditions a minimal constant droplet size is obtained, if all surfactant is adsorbed $[26,30]$.

In case of the varied homogenization pressure, a higher volume specific energy input leads to a droplet size reduction as long as there is sufficient emulsifier to adsorb at the generated interface and prevent recoalescence [24, 26, 30, 31]. Using a high pressure valve homogenizer, the intensity of droplet disruption can be increased by either recirculating the emulsion through the system or by applying higher pressure levels [16, 26, 31]. Hence, the oil droplet size is determined by the limiting factor: either the emulsifier concentration in the "surfactant-poor"- or the energy input in the "surfactant-rich" regime [25, 26].

\section{SLS versus NMR}

Besides SLS, the $d_{3,2}$ of oil droplets in emulsions was determined by NMR (Fig. 2) and also decreased with an increasing protein to oil ratio and homogenization pressure. Even though the trend was the same as for the $d_{3,2}$ measured by SLS, the diameter values differed between the methods. For protein to oil ratios $\leq 0.07$ and homogenization pressures

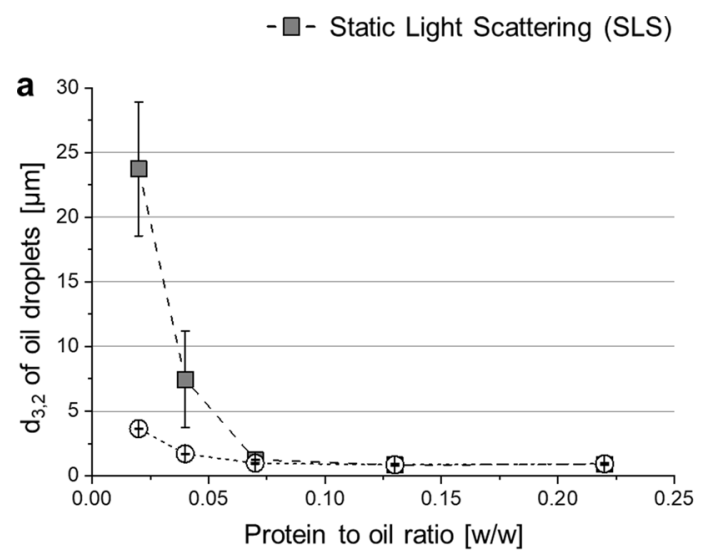

\section{- Nuclear Magnetic Resonance (NMR)}

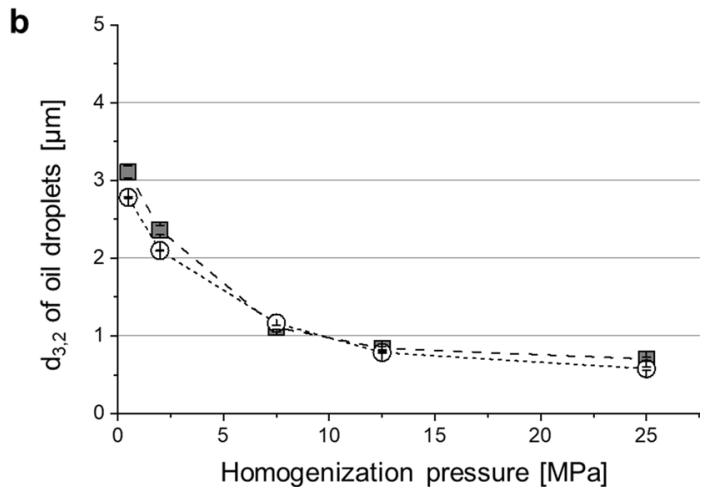

Fig. 2 Sauter mean diameter $\left(d_{3,2}\right)$ of oil droplets in feed emulsions determined by SLS and NMR as a function of the protein to oil ratio (a) and the homogenization pressure $(\mathbf{b})$ 
$\leq 2 \mathrm{MPa}$ the $d_{3,2}$ determined by NMR was significantly lower compared to the value obtained by SLS. For instance, a protein to oil ratio of 0.02 resulted in a $d_{3,2}$ of $23.73 \pm 5.17$ and $3.65 \pm 0.04 \mu \mathrm{m}$ for SLS and NMR measurement, respectively, which corresponds to a difference by a factor of 6.5 . For oil droplets $\leq 1.1 \mu \mathrm{m}$ the difference between the $d_{3,2}$ measured by the SLS and NMR was not significant, expect for a homogenization pressure of 12.5 and $25 \mathrm{MPa}$. Even though the deviation was statistically significant, the absolute difference was in the range of a few nanometers, indicating that the droplet size was rather similar.

In literature a good agreement between the oil droplet size determined by laser light scattering techniques and NMR was reported [21, 32-34]. It is suggested that the discrepancy obtained in this study is related to the presence of droplet clusters and their effect on droplet size quantification by the respective methods [21]. As SLS determines the oil droplet diameter optically by laser diffraction, a droplet cluster is considered as a single oil droplet and its overall size measured. In contrast, NMR measures the displacement of the self-diffusing oil molecules in each individual droplet, which is restricted by the droplet wall. Hence, the average size of individual droplets present in a cluster is calculated [33-39]. Exemplary light microscopic images confirm the presence of oil droplet clusters, in particular, for emulsions with low protein to oil ratios (Fig. 3).

Even though flocculation occurred and clusters were formed, individual droplets seemed to be rather stable against coalescence as the $d_{3,2}$ determined after $24 \mathrm{~h}$ changed only slightly and phase separation was not visually observed (Table 1). Gestranius et al. measured the droplet size of creaming layers over time by NMR and also found oil droplets that were stable against coalescence, even though flocculation occurred [40]. Further Kolanowski et al. observed a tendency of small droplets forming aggregates, which were visually stable for at least $3 \mathrm{~h} \mathrm{[41].}$

\section{Impact of emulsion properties on physical powder characteristics}

Feed emulsions were spray dried and the physical properties of the microencapsulated oil powders analyzed (Table 1). As the water activity and moisture content were between $0.190 \pm 0.006$ and $0.330 \pm 0.007$ and $2.96 \pm 0.02$ and $3.94 \pm 0.03 \%$, respectively, the spray dried particles were considered to be sufficiently dry. The average powder particle size differed between $86.2 \pm 3.5$ and $168.9 \pm 13.4 \mu \mathrm{m}$, which might be explained by varying emulsion viscosities and a widely spread size distribution indicating the presence of agglomerates, which was confirmed on SEM images (images not shown).

In order to gain more insights about the effect of spray drying, the $d_{3,2}$ of oil droplets in the feed emulsion and in the powder particles after spray drying is compared. In fig. 4 the $d_{3,2}$ (determined by NMR) of oil droplets in the emulsion and in the powder particles before and after removing the non-encapsulated oil is plotted as a function of the modified parameters. In addition, the $\mathrm{EE}$ is given on the $y$-axis.

The EE increases with the protein concentration and with the homogenization pressure until a plateau of $93.33 \pm 0.88 \%$ was reached. This indicates that large oil droplets result in more non-encapsulated oil, which supports the proposed concept.

As previously discussed, the emulsion droplet size decreased with the protein to oil ratio and with the homogenization pressure approaching a diameter $\leq 1 \mu \mathrm{m}$. The
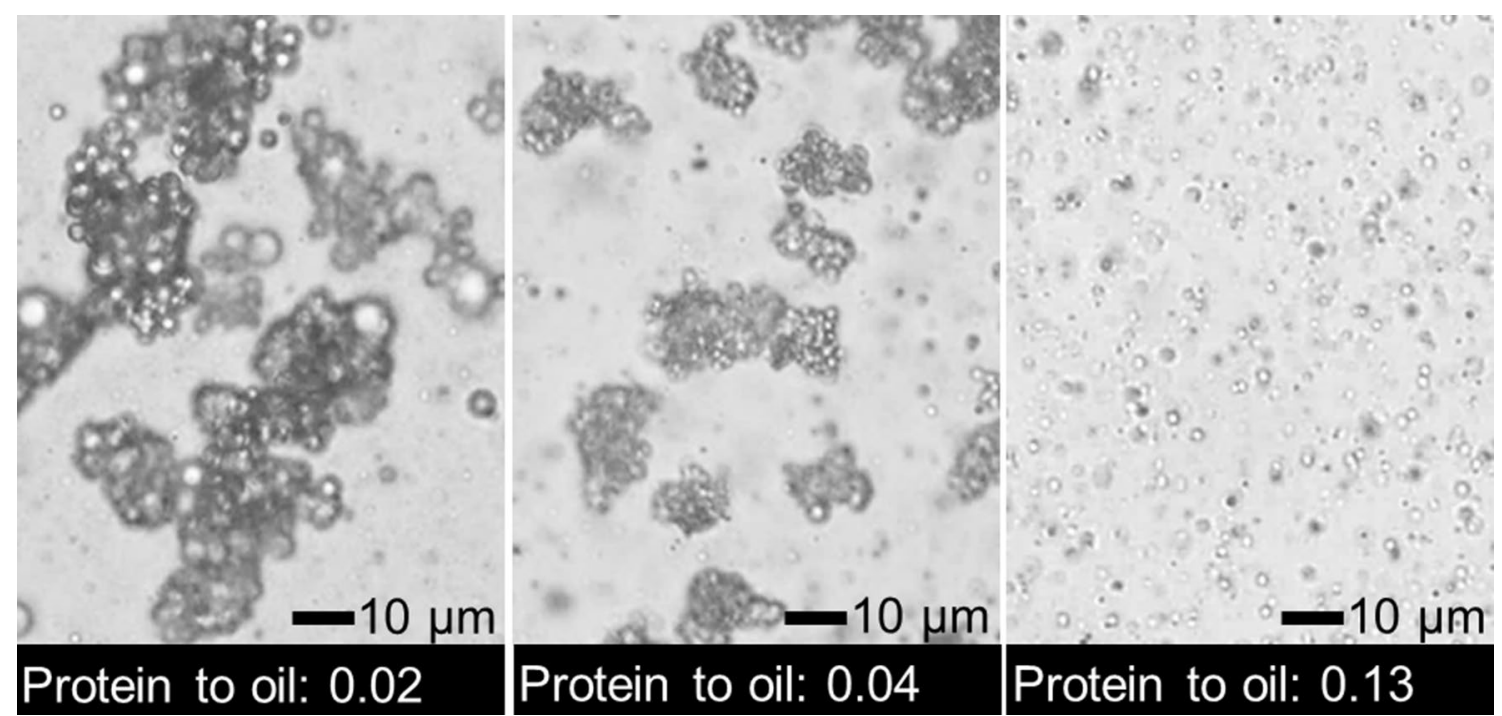

Fig. 3 Exemplary light microscope images of oil droplets in the feed emulsion with a protein to oil ratio of $0.02,0.04$ and 0.13 (w/w) 


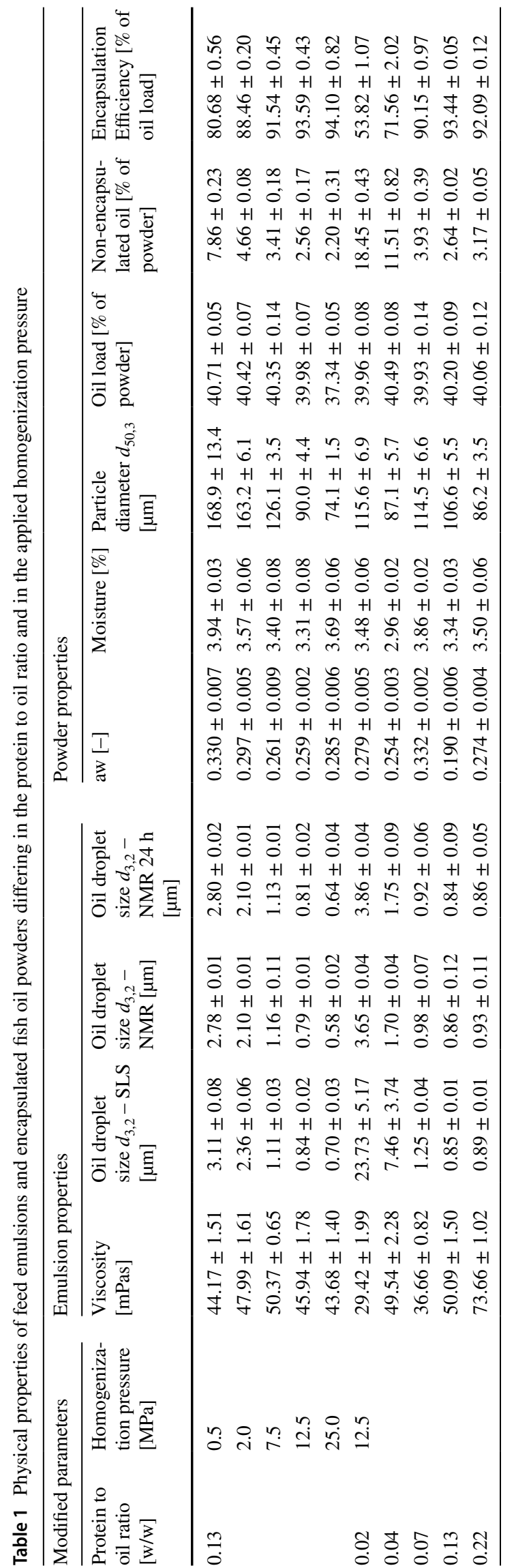

difference in size of encapsulated oil droplets was also cornfirmed on SEM images provided for three exemplary powders (Fig. 5 right). The spheres inside the particles represent the encapsulated oil, as the size corresponds to the measured oil droplet diameter and similar structures were reported in literature [18, 42, 43].

Comparing the oil droplets size (determined by NMR, Fig. 4) in the emulsion and in the powder after spray drying shows, that the $d_{3,2}$ decreased for feed emulsions with a diameter above $1 \mu \mathrm{m}$. The reduction was statistically significant for protein to oil ratios $\leq 0.04$ and homogenization pressures $\leq 2 \mathrm{MPa}$ and in particular pronounced for the lowest protein to oil ratio with a $d_{3,2}$ of $3.65 \pm 0.04$ and $2.27 \pm 0.05 \mu \mathrm{m}$ for oil droplets in the emulsion and in the powder, respectively. For other samples the difference between the $d_{3,2}$ before and after spray drying was not significant, with an exception of those being homogenized at 12.5 and $25 \mathrm{MPa}$. However, as the deviation was in the magnitude of a few nanometers, the droplet size in the emulsion and powder was similar.

Linke et al. reported a good agreement between the $d_{3,2}$ of oil droplets in liquid and dried emulsions, demonstrating that NMR is suitable to measure the size of oil droplets embedded within a solid matrix [21]. Therefore, it is assumed, that the lower $d_{3,2}$ after spray drying originates from the instability of oil droplets that are in contact with the powder particle surface and contribute to the non-encapsulated oil. If these oil droplets lose their spherical shape, they are not considered during the NMR measurement [40]. As large oil droplets are more likely to contribute to the non-encapsulation oil than small ones, the average diameter of remaining oil droplets decreases.

This assumption is supported by large oil droplets being in general less stable and thereby more likely to deform when they are located on the powder surface. In addition, the effect was more pronounced for powders with low protein concentrations promoting oil droplet instability, too [26]. Considering the morphology of three exemplary powders with protein to oil ratios of $0.02,0.04$ and 0.13 (Fig. 5, left), dark grey patches are distributed on the powder surface and are located between two particles. These dark areas represent oil, which was confirmed by EDX measurements resulting in approximately three times more $\mathrm{C}$ atoms in the dark compared to the light grey areas (data not shown). As these dark patches are spilled over the particle surface the hypothesis is supported, that oil droplets on the powder surface do not necessarily remain spherical. In contrast, for samples with an oil droplet size of $\leq 1 \mu \mathrm{m}$ no dark patches are visible on the particle surface (Fig. 5, lower row). This explains that the difference between the $d_{3,2}$ in the emulsion and in the powder was either not significant or very small. 
$\mathrm{d}_{3,2}$ of oil droplets $[\mu \mathrm{m}]:-\square-$ in the emulsion $\cdots \cdots$ in the powder $-\Delta \cdots$ after removing the non-encapsualted oil $\diamond$ Encapsulation Efficiency

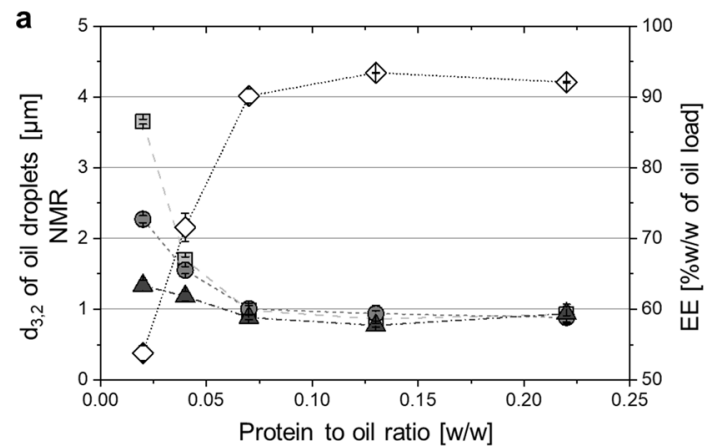

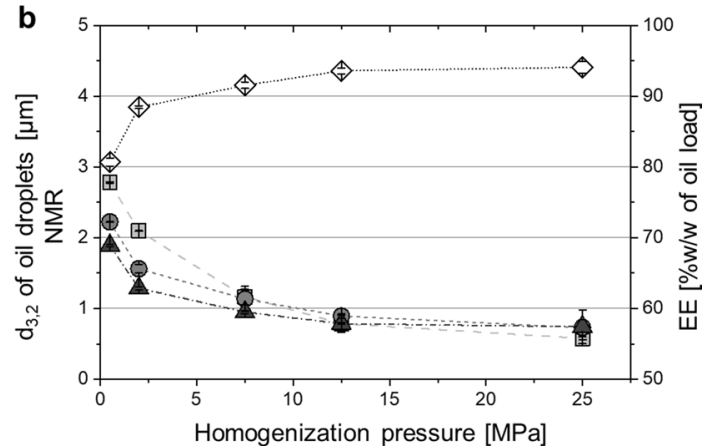

Fig. 4 Sauter mean diameter $\left(d_{3,2}\right)$ of oil droplets in feed emulsions, in powder particles and after removing the non-encapsulated oil determined by NMR ( $x$-axis) and encapsulation efficiency ( $y$-axis) as a function of the protein to oil ratio (a) and the homogenization pressure (b)

Also Gestranius et al. observed a decrease in the average oil droplet size over time for emulsions with less stabilizer (determined by NMR), which they explained by coalescence of large droplets being not further considered during measurement [40]. Abd Ghani et al. determined the $\mathrm{d}_{4,3}$ of oil droplets in the feed and reconstituted emulsions by laser scattering. As observed in this study, for feed emulsion droplets with a $\mathrm{d}_{4,3}>1 \mu \mathrm{m}$ the diameter was smaller after reconstitution, which they related to droplet disruption during atomization [18]. An alternative explanation might be, that surface oil droplets were not considered during the laser scattering, due to an inhomogeneous dispersion after reconstitution leading to a smaller $\mathrm{d}_{4,3}$. Soottitantawat et al. concluded that a reduced size of coarse flavor emulsion droplets after atomization was due to breakdown and evaporation in the rotating atomizer [15]. Even though the behavior of flavor droplets might be different compared to non-volatile oil, large droplets might not be considered during light scattering due to their instability.

For feed emulsions with a diameter above $1 \mu \mathrm{m}$, removing the surface oil led to an additional reduction of the $d_{3,2}$ compared to the powder, which was statistically significant for samples being homogenized at pressures $\leq 7.5 \mathrm{MPa}$ and with a protein to oil ratios below 0.22 . In case of the lowest protein to oil ratio, the $d_{3,2}$ of droplets in the powder before and after removing the non-encapsulated oil was $2.27 \pm 0.05$ and $1.33 \pm 0.08 \mu \mathrm{m}$, respectively. It is assumed, that some oil droplets that are in contact with the powder particle surface remained spherical after drying; e.g. oil droplets or droplet clusters that are almost completely embedded within the matrix, but still in contact with the particle surface. By removing these droplets, the $d_{3,2}$ of the remaining encapsulated oil decreases. This is supported by the fact that after surface oil removal dark spots appeared on the particle surface which might be holes previously filled with oil (Fig. 5 middle). The number and size was pronounced for powders with more non-encapsulated oil.

\section{Impact of the oil droplet size on the encapsulation efficiency}

In order to investigate the effect of the oil droplet size on the amount of surface oil, the EE is plotted as a function of the $d_{3,2}$ of oil droplets. For the Sauter mean diameter determined by NMR, the EE significantly decreased with the $d_{3,2}$ (Fig. 6a), which was expected, as large oil droplets result in more non-encapsulated oil [11-17, 19]. Compared to the homogenization pressure, the impact of the protein concentration seemed to be more pronounced. However, plotting the $d_{3,2}$ determined by SLS instead of NMR, led to an alignment of the protein to oil ratio and the homogenization pressure (Fig. 6b). Consequently, apart from the size of individual droplets, the size of droplet clusters played a major role for the EE.

The formation of droplet clusters can be induced by a number of different mechanisms. Apart from emulsion instability and interactions, high pressure levels during homogenization potentially lead to flocculation, which is referred to as over-processing [21, 26, 30, 31]. For instance, Carmona et al. obtained a more efficient encapsulation for homogenization pressures up to $50 \mathrm{MPa}$. Increasing the pressure further resulted in a larger droplets due to over-processing and simultaneously in a lower EE [12]. Thus, in order to maximize the EE, not only high pressure levels should be applied to reduce the oil droplet size to a minimum, but also flocculation has to be prevented.

In Fig. 7, the theoretical EE was calculated as a function of the oil droplet size for different powder particle diameters as described by Linke et al. [20]. For the oil droplets the $d_{3,0}$ 


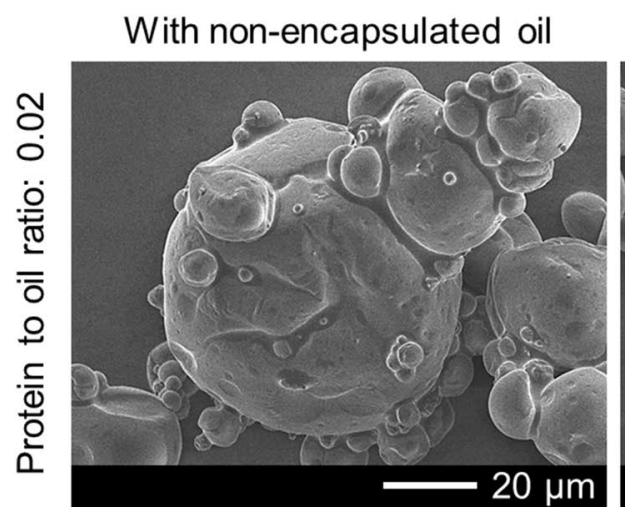

without non-encapsulated oil
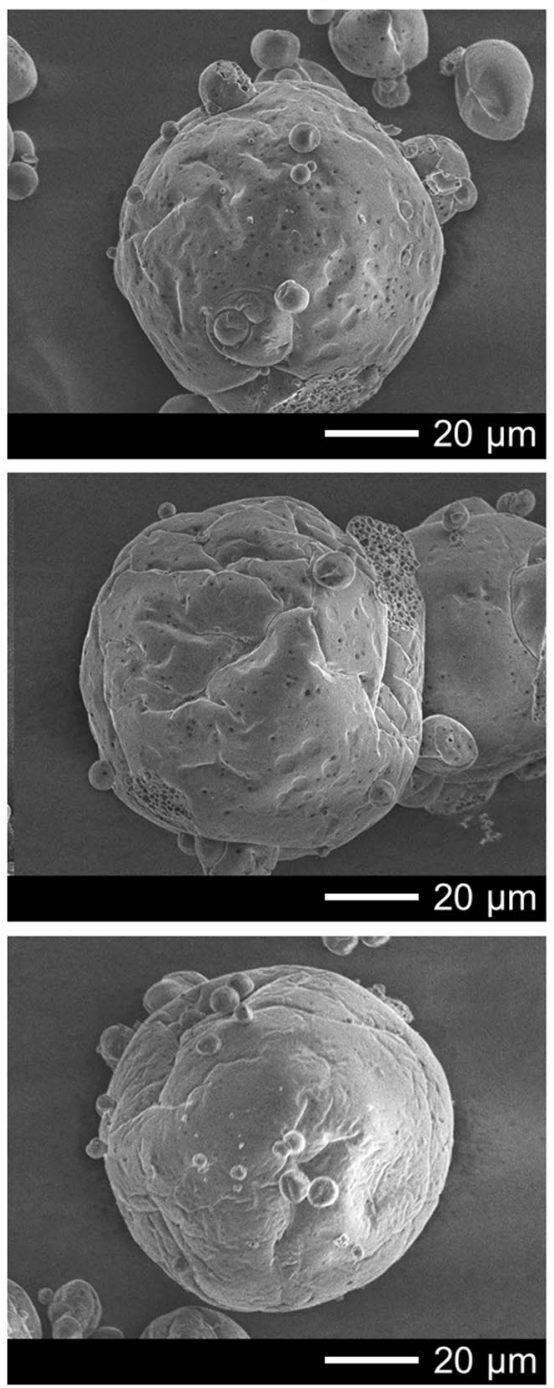

particle inside
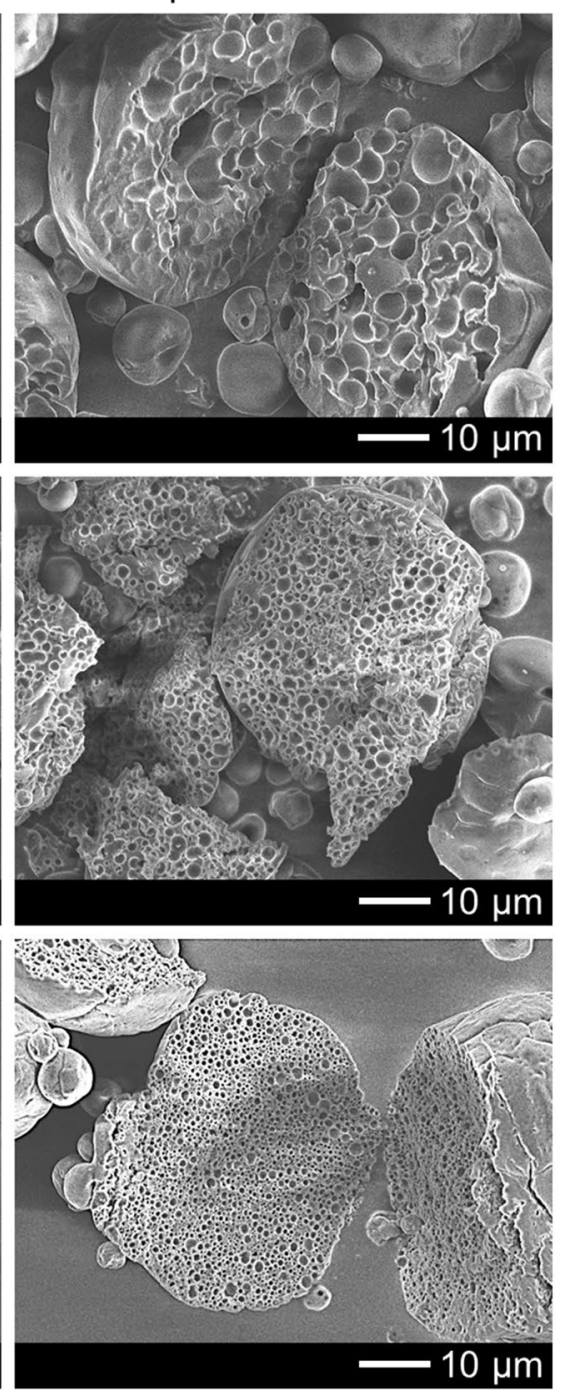

Fig. 5 Scanning electron microscope images of three exemplary encapsulated fish powders with protein to oil ratios of 0.02, 0.04 and 0.13 (w/w) (top, middle and bottom row, respectively); images with

was considered as it describes the mean volume over the number of droplets.

As expected, the theoretical EE decreases with the oil droplet size. The experimental data follow the same trend and fall in the same range, which supports the proposed theory, that the EE is determined by the probability of oil droplets and in particular droplet clusters being in contact with the powder particle surface. The results are in accordance with Abd Ghani et al., who related the theoretical encapsulation yield to the ratio of reconstituted droplet diameter to particle diameter [18]. Also Jafari et al. suggested that increasing the ratio of the droplet to the powder particle size will lower the amount of surface oil [11].

As an exception, the emulsion with the largest oil droplets had a higher experimentally determined EE than the an 850-fold magnification of powders with and without non-encapsulated oil are provided (first and second column, respectively), as well as of the particle inside with a 1500 -fold magnification

theoretical one. This sample corresponds to the lowest protein to oil ratio, which resulted in large droplet clusters. The deviation between the experimental and the theoretical EE might be related to an overestimation of the cluster size caused by model assumptions of the SLS method. Additionally, the oil droplet and particle diameter do not differ much from each other, so that the stochastic spatial distribution of oil droplets within the powder particle is not valid anymore, leading to an underestimation of the EE. Further, the particle size distribution of powders was widely spread (data not shown). By considering the median diameter of powder particles, in addition, deviations in the size might contribute to the discrepancy.

In literature, the effect of large oil droplets on the EE is often explained by the disruption of large oil droplets during 


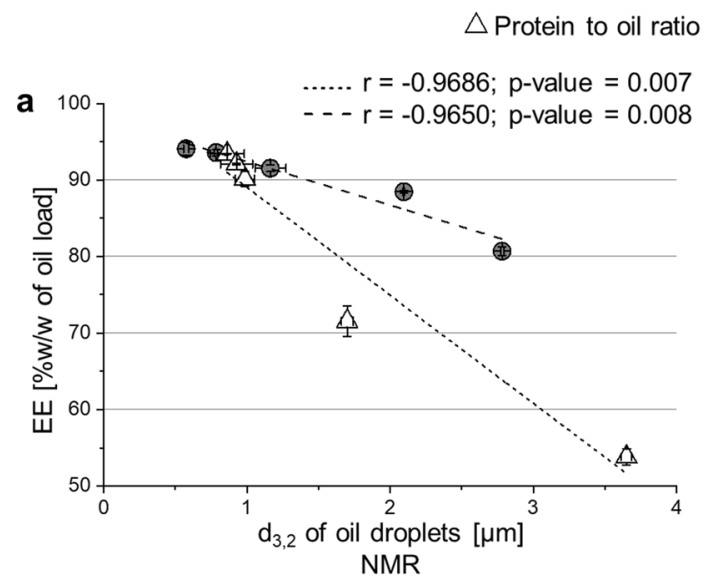

Homogenization pressure

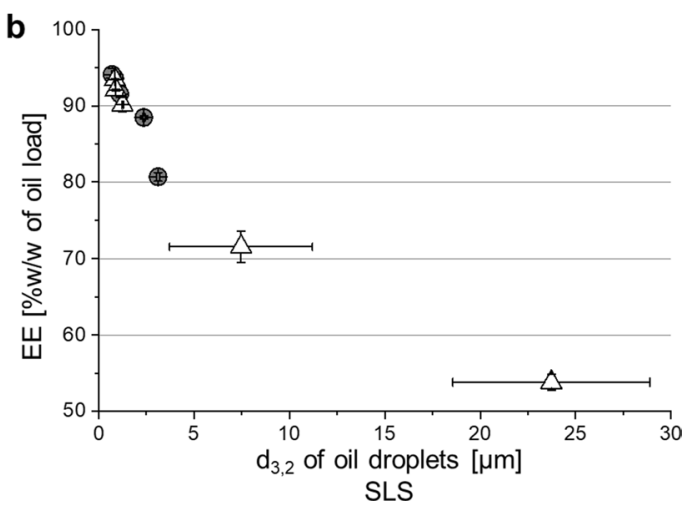

Fig. 6 Measured encapsulation efficiency as a function of the Sauter mean diameter $\left(d_{3,2}\right)$ of emulsion oil droplets determined by NMR (a) and SLS (b) for feed emulsions differing the protein to oil ratio and in the applied homogenization pressure

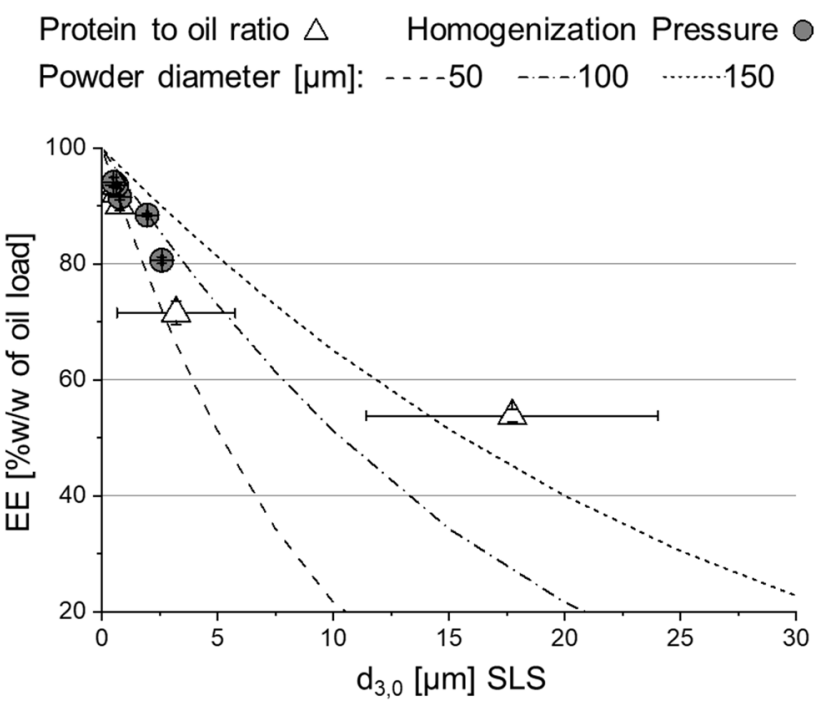

Fig. 7 Theoretical encapsulation efficiency (lines) calculated based on the diameter of oil droplets and powder particles and measured EE (data points) as a function of the $d_{3,0}$ of emulsion oil droplets determined by SLS for feed emulsions differing the protein to oil ratio and in the applied homogenization pressure

atomization leading to more non-encapsulated oil $[15,18$, 19]. As feed emulsions were homogenized a high pressure level, the remaining large oil droplets were typically in the range to 2 to $10 \mu \mathrm{m}$. Based on the high energy input required to disrupt such droplets during homogenization, it seems rather unlikely, that the energy input during atomization by a rotary disc or two fluid nozzle is sufficient to disrupt these oil droplets further, even though Munoz Ibanez et al. and Soottinitantawat et al. concluded that this can occur $[15,43]$. Nevertheless, in this study it was demonstrated that large oil droplets are more likely to contribute to the non-encapsulated oil and also lose their spherical shape. If this phenomenon occurs during atomization, drying or in the final powder has to be investigate in further studies.

\section{Conclusion}

Especially when using high pressure nozzles, droplet disruption cannot be excluded as a cause for surface oil generation. However, large oil droplets will lead to a decreased encapsulation efficiency by itself. The EE can be maximized by creating emulsions with a narrow distribution, a $d_{3,2}$ below $1 \mu \mathrm{m}$ and in particular without droplet clusters. Consequently, the emulsifier concentration and homogenization procedure has to be individually adjusted depending on the emulsion composition. The experimentally determined $\mathrm{EE}$ is in accordance with the theoretical one, supporting the concept, that the EE is determined by the probability of oil droplets being in contact with the powder particle surface. For emulsions with droplets $>1 \mu \mathrm{m}$, the $d_{3,2}$ decreases from the emulsion to the powder and further by removing the nonencapsulated oil, due to large oil droplets contributing the surface oil and losing their spherical shape. To understand, if this deformation occurs during atomization, drying or in the final powder, additional research is required.

Acknowledgements Open Access funding provided by Projekt DEAL. The authors acknowledge special thanks for the support by BASF Personal Care and Nutrition GmbH (Illertissen, Germany) providing fish oil. Furthermore, the author acknowledges generous support by the bioeconomy graduate program BBW ForWerts, supported by the MWK. All authors read and approved the final manuscript. 
Funding This study was funded by the Ministry of Science, Research and the Arts of Baden-Württemberg (MWK) under Grant [Az: 7533-10-5-87].

\section{Compliance with ethical standards}

Conflict of interest The authors declare that they have no conflict of interest.

Open Access This article is licensed under a Creative Commons Attribution 4.0 International License, which permits use, sharing, adaptation, distribution and reproduction in any medium or format, as long as you give appropriate credit to the original author(s) and the source, provide a link to the Creative Commons licence, and indicate if changes were made. The images or other third party material in this article are included in the article's Creative Commons licence, unless indicated otherwise in a credit line to the material. If material is not included in the article's Creative Commons licence and your intended use is not permitted by statutory regulation or exceeds the permitted use, you will need to obtain permission directly from the copyright holder. To view a copy of this licence, visit http://creativecommons.org/licenses/by/4.0/.

\section{References}

1. Beindorff CM, Zuidam NJ (2010) Microencapsulation of fish oil. In: Zuidam NJ (ed) Encapsulation technologies for active food ingredients and food processin. Springer, New York, NY, pp 161-185

2. Jafari SM, Assadpoor E, He Y, Bhandari B (2008) Encapsulation efficiency of food flavours and oils during spray drying. Dry Technol 26:816-835. https://doi.org/10.1080/073739308021359 72

3. Reineccius GA, Yan C (2016) Factors controlling the deterioration of spray dried flavourings and unsaturated lipids. Flavour Fragr J 31:5-21. https://doi.org/10.1002/ffj.3270

4. Zhou H, Yuan X, Zhao Q, Zhao B, Wang X (2013) Determination of oxygen transmission barrier of microcapsule wall by crocetin deterioration kinetics. Eur Food Res Technol 237:639-646. https ://doi.org/10.1007/s00217-013-2022-x

5. Baik M-Y, Suhendro EL, Nawar WW, McClements DJ, Decker EA, Chinachoti P (2004) Effects of antioxidants and humidity on the oxidative stability of microencapsulated fish oil. J Am Oil Chem Soc 81:355-360. https://doi.org/10.1007/s1174 6-004-0906-7

6. Linke A, Weiss J, Kohlus R (2020) Oxidation rate of the nonencapsulated- and encapsulated oil and their contribution to the overall oxidation of microencapsulated fish oil particles. Food Res Int 127:108705. https://doi.org/10.1016/j.foodres.2019.108705

7. Drusch S, Berg S (2008) Extractable oil in microcapsules prepared by spray-drying: localisation, determination and impact on oxidative stability. Food Chem 109:17-24. https://doi.org/10.1016/j. foodchem.2007.12.016

8. Aghbashlo M, Mobli H, Rafiee S, Madadlou A (2012) Optimization of emulsification procedure for mutual maximizing the encapsulation and exergy efficiencies of fish oil microencapsulation. Powder Technol 225:107-117. https://doi.org/10.1016/j.powte c. 2012.03 .040

9. Velasco J, Holgado F, Dobarganes C, Márquez-Ruiz G (2009) Influence of relative humidity on oxidation of the free and encapsulated oil fractions in freeze-dried microencapsulated oils. Food Res Int 42:1492-1500. https://doi.org/10.1016/j.foodr es.2009.08.007
10. Hardas N, Danviriyakul S, Foley JL, Nawar WW, Chinachoti P (2002) Effect of relative humidity on the oxidative and physical stability of encapsulated milk fat. J Am Oil Chem Soc 79:151158. https://doi.org/10.1007/s11746-002-0450-5

11. Jafari SM, He Y, Bhandari B (2007) Encapsulation of nanoparticles of d-limonene by spray drying: role of emulsifiers and emulsifying techniques. Dry Technol 25:1069-1079. https://doi. org/10.1080/07373930701396758

12. Carmona PAO, Tonon RV, da Cunha RL, Hubinger MD (2013) Influence of emulsion properties on the microencapsulation of orange essential oil by spray drying. J Colloid Sci Biotechnol 2:130-139. https://doi.org/10.1166/jcsb.2013.1042

13. Danviriyakul S, McClements DJ, Decker E, Nawar WW, Chinachoti P (2002) Physical stability of spray-dried milk fat emulsion as affected by emulsifiers and processing conditions. J Food Sci 67:2183-2189. https://doi.org/10.1111/j.1365-2621.2002.tb095 24.X

14. Shamaei S, Seiiedlou SS, Aghbashlo M, Tsotsas E, Kharaghani A (2017) Microencapsulation of walnut oil by spray drying: effects of wall material and drying conditions on physicochemical properties of microcapsules. Innov Food Sci Emerg Technol 39:101-112. https://doi.org/10.1016/j.ifset.2016.11.011

15. Soottitantawat A, Yoshii H, Furuta T, Ohkawara M, Linko P (2003) Microencapsulation by spray drying: influence of emulsion size on the retention of volatile compounds. J Food Sci 68:22562262. https://doi.org/10.1111/j.1365-2621.2003.tb05756.x

16. Shiga H, Neoh TL, Ninomiya A, Adachi S, Lopez I, Adachi S, Yoshii H (2017) Effect of oil droplet size on the oxidative stability of spray-dried flaxseed oil powders. Biosci Biotechnol Biochem 8451:1-7. https://doi.org/10.1080/09168451.2017.1281720

17. Abd Ghani A, Matsumura K, Yamauchi A, Shiga H, Adachi S, Izumi H, Yoshii H (2016) Effects of oil-droplet diameter on the stability of squalene oil in spray-dried powder. Dry Technol 34:1726-1734. https://doi.org/10.1080/07373937.2016.1190936

18. Abd Ghani A, Adachi S, Sato K, Shiga H, Iwamoto S, Neoh TL, Adachi S, Yoshii H (2017) Effects of oil-droplet diameter and dextrose equivalent of maltodextrin on the surface-oil ratio of microencapsulated fish oil by spray drying. J Chem Eng Jpn 50:799-806. https://doi.org/10.1252/jcej.17we048

19. Tonon RV, Grosso CRF, Hubinger MD (2011) Influence of emulsion composition and inlet air temperature on the microencapsulation of flaxseed oil by spray drying. Food Res Int 44:282-289. https://doi.org/10.1016/j.foodres.2010.10.018

20. Linke A, Linke T, Hinrichs J, Kohlus R (2019) Factors determining the surface oil concentration of encapsulated lipid particles - impact of the spray drying conditions. Dry Technol. https://doi. org/10.1080/07373937.2019.1648287

21. Linke A, Anzmann T, Weiss J, Kohlus R (2017) Advanced characterisation of encapsulated lipid powders regarding microstructure by time domain-nuclear magnetic resonance. J Microencapsul 34:140-150. https://doi.org/10.1080/02652048.2017.1300198

22. Wang M, Feng M, Jia K, Sun J, Xu X, Zhou G (2017) Food Hydrocolloids Effects of flaxseed gum concentrations and $\mathrm{pH}$ values on the stability of oil-in-water emulsions. Food Hydrocoll 67:54-62. https://doi.org/10.1016/j.foodhyd.2017.01.004

23. Garcia LC, Tonon RV, Hubinger MD (2012) Effect of homogenization pressure and oil load on the emulsion properties and the oil retention of microencapsulated basil essential oil (Ocimum basilicum L.). Dry Technol 30:1413-1421. https://doi. org/10.1080/07373937.2012.685998

24. Walstra P (2003) Physical chemistry of foods. Marcel Dekker Inc, Basel. https://doi.org/10.1016/j.ejpb.2003.10.013

25. Tcholakova S, Denkov ND, Ivanov IB, Campbell B (2006) Coalescence stability of emulsions containing globular milk proteins. Adv Colloid Interface Sci 123-126:259-293. https://doi. org/10.1016/j.cis.2006.05.021 
26. McClements DJ (2016) Food emulsions - principles, practices and techniques, 3rd edn. CRC Press Taylor \& Francis Group, Boca Raton

27. Hu M, McClements DJ, Decker EA (2003) Lipid oxidation in corn oil-in-water emulsions stabilized by casein, whey protein isolate, and soy protein isolate. J Agric Food Chem 51:1696-1700. https ://doi.org/10.1021/jf020952j

28. Silva VM, Vieira GS, Hubinger MD (2014) Influence of different combinations of wall materials and homogenisation pressure on the microencapsulation of green coffee oil by spray drying. Food Res Int 61:132-143. https://doi.org/10.1016/j.foodres.2014.01.052

29. Sørensen A-DM, Baron CP, Let MB, Brüggemann DA, Pedersen LRL, Jacobsen C (2007) Homogenization conditions affect the oxidative stability of fish oil enriched milk emulsions: oxidation linked to changes in protein composition at the oil-water interface. J Agric Food Chem 55:1781-1789. https://doi.org/10.1021/jf062 3900

30. Jafari SM, Assadpoor E, He Y, Bhandari B (2008) Re-coalescence of emulsion droplets during high-energy emulsification. Food Hydrocoll 22:1191-1202. https://doi.org/10.1016/j.foodh yd.2007.09.006

31. Huynh TV, Caffin N, Dykes G, Bhandari B (2008) Optimization of the microencapsulation of lemon myrtle oil using response surface methodology. Dry Technol 26:357-368. https://doi. org/10.1080/07373930801898182

32. Kiokias S, Reszka AA, Bot A (2004) The use of static light scattering and pulsed-field gradient NMR to measure droplet sizes in heat-treated acidified protein-stabilised oil-in-water emulsion gels. Int Dairy J 14:287-295. https://doi.org/10.1016/j.idair yj.2003.09.007

33. Goudappel GJW, Van Duynhoven JPM, Mooren MMW (2001) Measurement of oil droplet size distributions in food oil/water emulsions by time domain pulsed field gradient NMR. J Colloid Interface Sci 239:535-542. https://doi.org/10.1006/jcis.2001.7603

34. Van Duynhoven JPM, Goudappel GJW, Van Dalen G, Van Bruggen PC, Blonk JCG, Eijkelenboom APAM (2002) Scope of droplet size measurements in food emulsions by pulsed field gradient NMR at low field. Magn Reson Chem 40:51-59. https://doi. org/10.1002/mrc. 1115

35. Voda MA, van Duynhoven JPM (2009) Characterization of food emulsions by PFG NMR. Trends Food Sci Technol 20:533-543. https://doi.org/10.1016/j.tifs.2009.07.001
36. Bot A, Duval FP, Duif CP, Bouwman WG (2007) Probing the droplet cluster structure in acidified temperature- cycled o/w emulsion gels by means of SESANS. Int J Food Sci Tech 42:746752. https://doi.org/10.1111/j.1365-2621.2007.01539.x

37. van Duynhoven JPM, Maillet B, Schell J, Tronquet M, Goudappel G-JW, Trezza E, Bulbarello A, Van Dusschoten D (2007) A rapid benchtop NMR method for determination of droplet size distribution in food emulsions. Eur J Lipid Sci Technol 109:1095-1103. https://doi.org/10.1002/ejlt.200700019

38. Todt H, Burk W, Guthausen G, Guthausen A, Kamlowski A, Schmalbein D (2001) Quality control with time-domain NMR. Eur J Lipid Sci Technol 103:835-840. https://doi.org/10.1002/14389312(200112)103:12<835:AID-EJLT835>3.0.CO;2-P

39. Guthausen G, Todt H, Burk W, Schmalbein D, Kamlowski A (2008) Time-domain NMR in quality control: more advanced methods. In: Webb GA (ed) Modern magnetic resonance. Springer, Dordrecht, pp 1735-1738

40. Gestranius M, Stenius P, Kontturi E, Sjöblom J, Tammelin T (2017) Colloids and Surfaces A : physicochemical and engineering aspects phase behaviour and droplet size of oil-in-water pickering emulsions stabilised with plant-derived nanocellulosic materials. Colloids Surf A Physicochem Eng Asp 519:60-70. https:// doi.org/10.1016/j.colsurfa.2016.04.025

41. Kolanowski W, Ziolkowski M, Weißbrodt J, Kunz B, Laufenberg G (2006) Microencapsulation of fish oil by spray drying — Impact on oxidative stability. Part 1. Eur Food Res Technol 222:336-342. https://doi.org/10.1007/s00217-005-0111-1

42. Abd Ghani A, Adachi S, Shiga H, Neoh TL, Adachi S, Yoshii H (2017) Effect of different dextrose equivalents of maltodextrin on oxidation stability in encapsulated fish oil by spray drying. Biosci Biotechnol Biochem 8:705-711. https://doi.org/10.1080/09168 451.2017.1281721

43. Munoz-Ibanez M, Azagoh C, Dubey BN, Dumoulin E, Turchiuli C (2015) Changes in oil-in-water emulsion size distribution during the atomization step in spray-drying encapsulation. J Food Eng 167:122-132. https://doi.org/10.1016/j.jfoodeng.2015.02.008

Publisher's Note Springer Nature remains neutral with regard to jurisdictional claims in published maps and institutional affiliations. 